\title{
Emergence of mupirocin resistance in multiresistant Staphylococcus aureus clinical isolates belonging to Brazilian epidemic clone III::B:A
}

\author{
R.L.B. RAMOS*, L.A. TEIXEIRA* $\dagger$, L.R. ORMONDE* $\ddagger$, P.L.A. SIQUEIRA*, M.S. SANTOS\&, \\ D. MARANGONI§ and A.M.S. FIGUEIREDO*†
}

* Universidade Federal do Rio de Janeiro, Instituto de Microbiologia Prof. Paulo de Góes, Laboratório de Biologia Molecular de Bactérias, Centro de Ciências da Saúde, Bloco 1, Cidade Universitária, Rio de Janeiro, RJ 21941.590, Brazil, †The Rockefeller University, 1230 York Avenue 10021, New York, NY, USA, ‡Instituto de Puericultura Martagão Gesteira, Universidade Federal do Rio de Janeiro and §Hospital Universitário Clementino Fraga Filho, Universidade Federal do Rio de Janeiro, Brazil

\begin{abstract}
Mupirocin is a topical antimicrobial agent that has been sucessfully used to eradicate methicillin-resistant Staphylococcus aureus from the anterior nares and other sites of patients and health care personnel. This report describes the acquisition of a novel mupirocin resistance gene (ileS) by an epidemic MRSA clone that is geographically widespread in Brazil.
\end{abstract}

\section{Introduction}

Hospital-acquired infections caused by methicillinresistant Staphylococcus aureus (MRSA) have increased in recent years $[1,2]$. These isolates are often resistant to many other antimicrobial agents $[3,4]$ and are sometimes involved in severe infections $[5,6]$. Prompt control measures may stop MRSA spread in a hospital, but once strains are established they often become endemic and extraordinary efforts may be necessary to stop nosocomial spread [2]. Colonisation of patients contributes to the increase in morbidity and mortality caused by these resistant bacteria. The selection of MRSA by antibiotic therapy may favour the establishment and predominance of these organisms in hospitals [7].

Mupirocin (pseudomonic acid A) is a topical antimicrobial agent, produced by Pseudomonas fluorescens, that has been used successfully to eradicate MRSA from the anterior nares and other sites of colonised patients and health care workers [8]. It has been used mainly in hospitals, with the result that mupirocin resistance has been transmitted both horizontally and vertically among $S$. aureus strains [9].

Received 3 March 1998; revised version accepted 26 June 1998.

Corresponding author: Dr A.M.S. Figueiredo (e-mail: immmasf@microbio.ufrj.br).
In Brazil, an epidemic MRSA clone that carries mecA polymorph III in combination with Tn554 pattern B, and exhibits pulsed-field gel electrophoresis pattern $A$ (clone III::B:A), has caused hospital outbreaks in seven different cities $[4,10]$, ranging from Manaus in the north to Porto Alegre $5300 \mathrm{~km}$ to the south. This report describes the acquisition of high-level mupirocin resistance by this epidemic, multiresistant $S$. aureus clone.

\section{Materials and methods}

\section{Bacterial strains}

Thirteen mupirocin-resistant isolates were obtained from Hospital Universitário Clementino Fraga Filho (HUCFF), Rio de Janeiro city, RJ, Brazil. Another three high-level mupirocin-resistant isolates were obtained from two other general hospitals (each $<400$ beds) in Rio de Janeiro city, where mupirocin has been widely used for MRSA nasal decontamination. The strains were isolated from the anterior nares of different patients during 1995 and 1996. All were identified as $S$. aureus by routine identification tests [11] and stored at $-70{ }^{\circ} \mathrm{C}$ in sterile glycerol $10 \%$.

\section{Antibiotic sensitivity testing}

Disk diffusion tests were performed as recommended by the National Committee for Clinical Laboratory Standards (NCCLS) [12]. The following disks (Cecon) 
were used: oxacillin $1 \mu \mathrm{g}$, cephalothin $30 \mu \mathrm{g}$, clindamycin $2 \mu \mathrm{g}$, benzylpenicillin $10 \mathrm{U}$, chloramphenicol $30 \mu \mathrm{g}$, ciprofloxacin $5 \mu \mathrm{g}$, erythromycin $15 \mu \mathrm{g}$, tetracycline $30 \mu \mathrm{g}$, gentamicin $10 \mu \mathrm{g}$, trime-thoprim $1.25 \mu \mathrm{g}$ plus sulphamethoxazole $23.75 \mu \mathrm{g}$, vancomycin $30 \mu \mathrm{g}$ and rifampicin $5 \mu \mathrm{g}$. A mupirocin $5-\mu \mathrm{g}$ disk was obtained from Oxoid.

The MIC of mupirocin was determined in solid medium by the method recommended by the NCCLS [13]. Trypticase Soy Agar (TSA) containing methicillin (Sigma) $25 \mathrm{mg} / \mathrm{L}$ was used to screen for methicillin resistance, as described previously [14].

\section{Molecular methods}

The procedures for $S$. aureus DNA preparations were as described previously [15], except that the staphylococcal cell wall was lysed with lysostaphin $(90 \mathrm{U} / \mathrm{ml})$. Escherichia coli plasmid DNA was prepared with the FlexPrep kit (Pharmacia Biotechnology) as recommended by the manufacturer. The fragment of the $E$. coli plasmid used as probe was purified electrophoretically from an agarose $0.8 \%$ gel by use of the Sephaglas Band Prep kit (Pharmacia) as recommended. The fluorescein-labelled probe was obtained by the Enhanced Chemiluminescence (ECL) Gene Labelling System as recommended by the manufacturer (Amersham).

The large plasmid harboured by the mupirocinresistant strains was excised from an agarose $0.8 \%$ gel after electrophoresis. The agarose-inserted plasmid DNA was digested with HindIII. The plasmid fragments were purified with the Band Prep kit and dot-blotted with nylon membranes as described previously [14]. The probe used was a $2.0-\mathrm{kb} X b a \mathrm{I}$ fragment of the plasmid pMZ1 [16].

Chromosomal DNA was digested with ClaI. The membranes were hybridised with the mecA probe and re-probed (after boiling) with Tn554. The hybridisation patterns involving mecA or Tn554 were identified by comparison with previously described types [17]. The DNA probe used was a 1.25-kb Pst I-XbaI fragment of the mecA gene cloned into pTZ219 [18]. A 5.5-kb EcoRV transposon-specific fragment was also used to detect the presence of Tn554 [19].

Genomic DNA was prepared and cut with the SmaI restriction enzyme as described previously [20]. Pulsed-field gel electrophoresis (PFGE) was performed as described [20] in a CHEF DR III apparatus, except that the voltage applied was $5.5 \mathrm{~V} / \mathrm{cm}^{2}$ (BioRad, Richmond, CA, USA). Methods used for staining, photographing, Southern hybridisation and probing of the gels have been described previously [15].

\section{Results}

The MICs of mupirocin for 16 arbitrarily chosen, highlevel mupirocin-resistant isolates from HUCFF and two other Rio de Janeiro hospitals varied from 512 to $2048 \mathrm{mg} / \mathrm{L}$. Their DNA hybridised with the novel ileS gene described previously [16] (Fig. 1).

Most of the strains were susceptible only to vancomycin, except those designated Mup 12-Mup 16, which were also susceptible to chloramphenicol. The mupirocin-resistant isolates were also methicillin resistant (Fig. 2) and were classified as heterogeneous class III or homogeneous class IV. Strains with these profiles produced a confluent lawn on agar containing methicillin $25 \mathrm{mg} / \mathrm{L}$ and grew up to the edge of a 1$\mu \mathrm{g}$ oxacillin disk.

Analysis of the genomic DNA by PFGE indicated a pattern similar to that of the epidemic Brazilian clonal type III::B:A (Fig. 3). The analysis of mecA-Cla I and Tn554 polymorphs in three of the isolates showed that they were also mecA-Cla I type III and Tn554 type B, similar to MRSA clonal type III::B:A (Fig. 4a, b).

\section{Discussion}

HUCFF is a 498-bed hospital for adult patients that has medical and surgical care, but no paediatric, obstetric or burns ward. MRSA have been reported in HUCFF

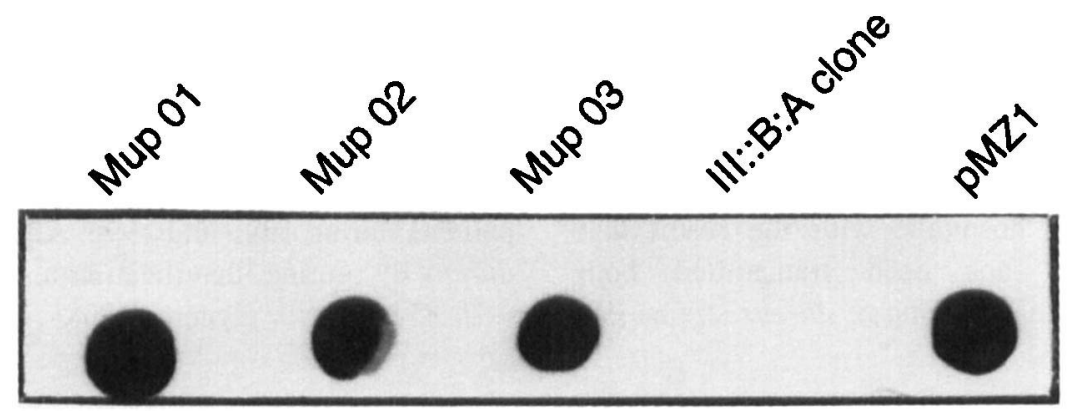

Fig. 1. Dot-blot hybridisation of HindIII restriction fragments of the large plasmid isolated from the mupirocinresistant $S$. aureus strains, designated as Mup 01,02 and 03, with a specific DNA probe for the novel ileS gene cloned in pMZ1 [16]. pMZ1 was used as positive control; total DNA obtained from a mupirocin-susceptible MRSA strain belonging to clonal type III::B:A was the negative control. 


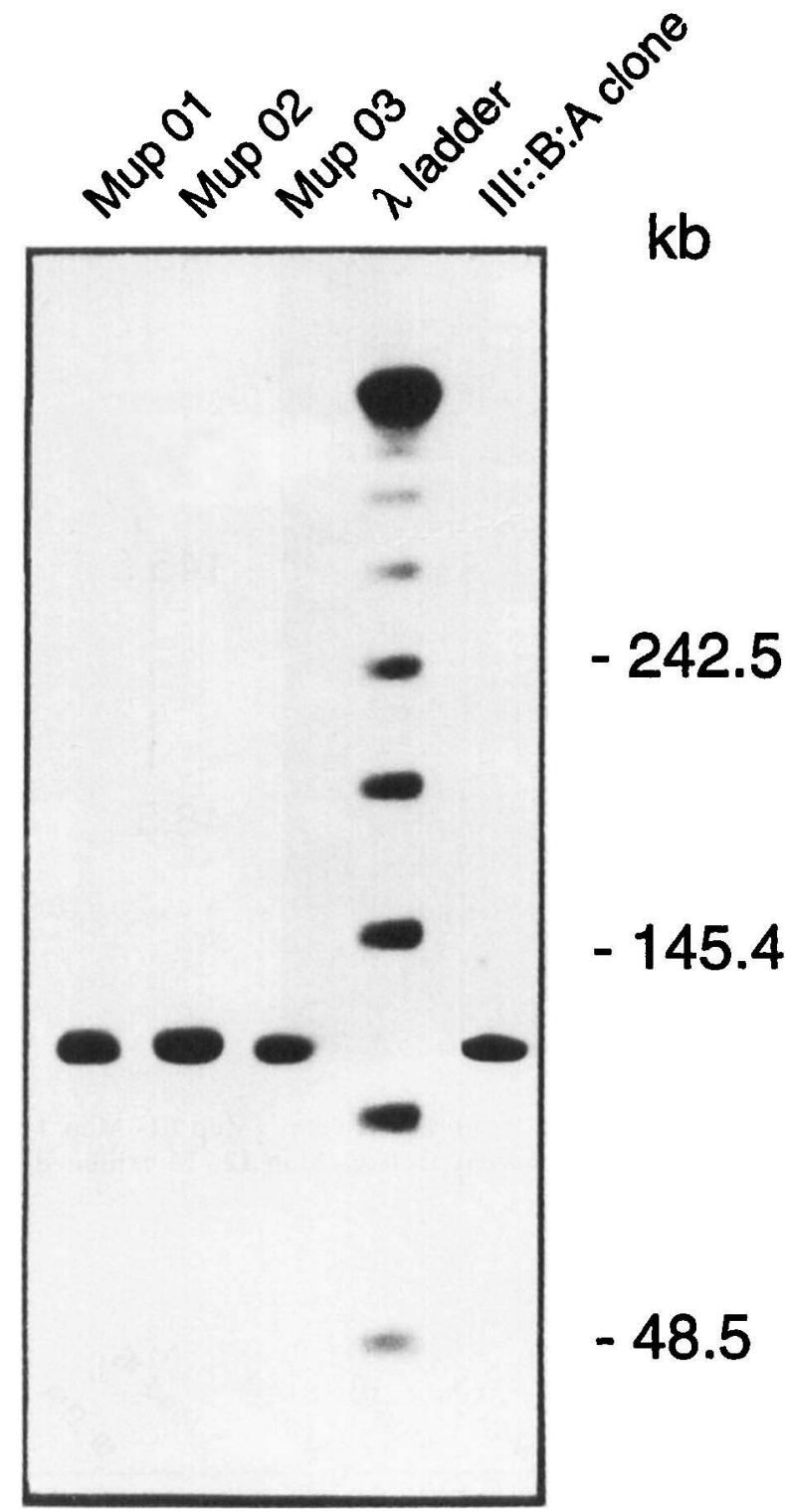

Fig. 2. Physical location of the mecA gene on SmaI-cut chromosomal DNA from the mupirocin-resistant $S$. aureus strains Mup 01, 02 and 03 and a mupirocinsusceptible clonal type III::B:A strain. After PFGE and Southern blotting the DNA was hybridised to the mecAspecific probe [18].

since 1987 , when the incidence was $c .7 .9 \%$ of the total $S$. aureus isolates. The incidence was c. $7.2 \%$ in 1988 , but increased to $33 \%$ in 1989 and has remained at this level (last tested October 1996). Topical mupirocin has been administered in this hospital for MRSA decontamination of patients and health care workers since 1990 and from that time screening for mupirocin resistance has been performed by the disk diffusion test. Very few mupirocin-resistant strains were detected in the hospital until 1994. In 1995 the incidence rose to c. $31 \%$ of MRSA isolates; from January 11996 to October 20 1996 , this incidence was c. $16 \%$.

The molecular mechanisms of mupirocin resistance are not clearly understood. In resistant bacteria, mupirocin cannot effectively bind to isoleucyl tRNA synthetase. Low-level mupirocin resistance (MIC 8$64 \mathrm{mg} / \mathrm{L}$ ) is probably caused by point mutations in the native gene that codes for the synthetase (ileS) [21]. High-level mupirocin resistance (MIC $>500 \mathrm{mg} / \mathrm{L}$ ) is associated with a novel ileS gene.

A previous study [4] showed that epidemic MRSA isolates belonging to clonal type III::B:A are spread over large distances $(5300 \mathrm{~km})$ of Brazil, from the north to the south of the country. Recent studies showed that this clone is present in two further Brazilian states $[10,22,23]$, bringing the number of Brazilian cities in which this clone is present to seven. This clone is also present in Argentina and Uruguay (Coimbra et al., unpublished observations). The predominance and spread of a unique MRSA clone between different countries has also been demonstrated in Europe [20, 24].

In the present study, analysis of the genomic DNA of mupirocin-resistant strains by PFGE revealed a pattern similar to that of the epidemic Brazilian clonal type III::B:A (Fig. 3), indicating that the novel ileS gene had been horizontally acquired by MRSA isolates. Acquisition of the novel ileS gene may have occurred after the introduction of mecA and transposon $\operatorname{Tn} 554$ into this $S$. aureus strain, as most isolates so far tested do not yet carry the novel ileS gene [4]. Some strains from clonal type III::B:A have also acquired staphylococcal enterotoxin ent genes [23], suggesting that the horizontal acquisition of genes occurs with considerable frequency among strains of this clonal type.

Purified DNA fragments obtained from the large plasmid observed in the mupirocin-resistant strains hybridised with the mupirocin-specific probe (Fig. 1), but the novel ileS gene was not detected in the chromosomal DNA fragments. These results indicate a plasmid location for the novel ileS gene, but this plasmiid has not been characterised further. Mupirocinresistant $S$. aureus isolates tested in the UK [21] and the USA [25] also carried the novel ileS gene inserted on a large plasmid. A plasmid encoding high-level mupirocin resistance obtained from Brazilian isolates could be transferred to strain RN8411 by filter-mating [26]. Transfer occurred at low frequencies, and this may explain the vertical spread of the novel ileS gene among isolates belonging to clonal type III::B:A.

Tracing the path of bacterial clones is important in the study of the variability and evolution of bacteria. It may also help epidemiologists to predict and control the extensive spread of a new resistance trait. This study has shown that isolates of the epidemic Brazilian clone III::B:A carrying the novel ileS gene are now present in at least three different hospitals in Rio. Although high-level mupirocin resistance is still rare and the study was thus limited by the number of isolates tested, it is noteworthy that the acquisition of 


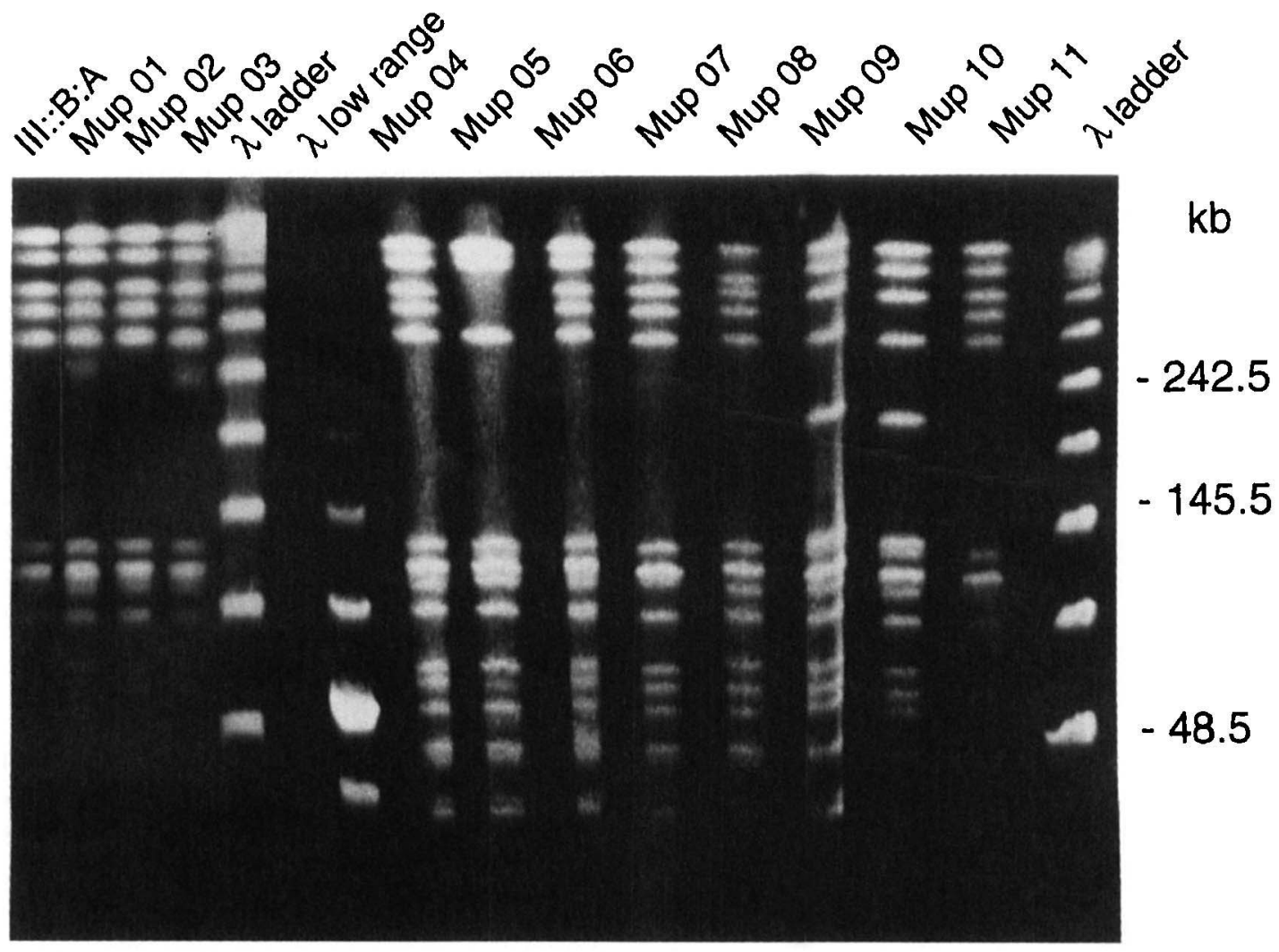

Fig. 3. PFGE of the SmaI-digested chromosomal DNA from mupirocin-resistant S. aureus isolates (Mup 01-Mup 11) and a mupirocin-susceptible MRSA strain belonging to clonal type III::B:A. S. aureus isolates Mup 12-16 exhibited a pattern identical to that of Mup 01-11.
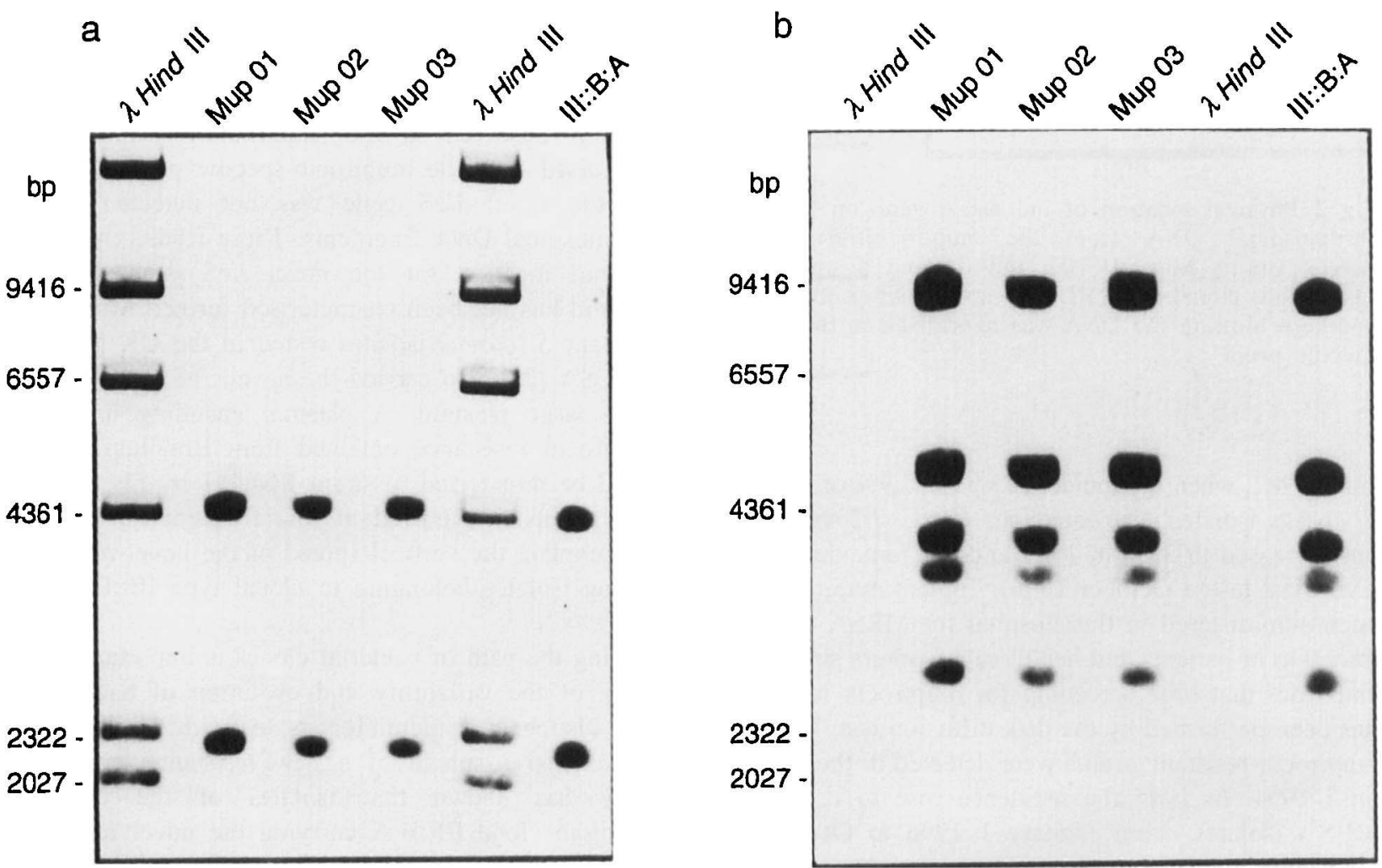

Fig. 4. Chromosomal DNA samples from the mupirocin-resistant $S$. aureus strains Mup 01, 02 and 03 and a mupirocinsusceptible clonal type III::B:A were digested with ClaI. After electrophoresis and Southern blotting the DNA was hybridised to: a, the mecA-specific probe [18]; b, the Tn554-derived probe. 
ileS gene was restricted to multiresistant $S$. aureus strains of a particular clonal type.

Because of the epidemic dissemination characteristic of this clone and the fact that mupirocin is widely used for MRSA decontamination in some hospitals in Brazil, the mupirocin resistance gene may spread quickly among MRSA isolates in this country (and possibly in South American neighbours), if measures to control the use of this antibiotic are not observed immediately.

We thank A. Tomasz for support and suggestions. We are also indebted to $K$. Dyke for kindly reviewing this manuscript and for providing the novel ileS gene probe. We thank $\mathrm{B}$. de Jonge for his helpful comments and Maria Cícera da Silva for technical assistance. This work was supported in part by a grant from Conselho Nacional de Desenvolvimento Científico e Tecnológico (CNPq), Fundação Coordenação de Aperfeiçoamento de Pessoal de Nivel Superior (Capes, Proim) and Financiadora de Estudos e projetos (FINEP/BID FINEP/PRONEX; FINEP/FNDCT)

This work was presented in part at the 97th General Meeting of the American Society for Microbiology, Miami Beach, USA, 4-8 May 1997 (abstract no. L6)

\section{References}

1. Boyce JM. Increasing prevalence of methicillin-resistant Staphylococcus aureus in the United States. Infect Control Hosp Epidemiol 1990; 11: 639-642.

2. Boyce JM, Jackson MM, Pugliese G et al. Methicillin-resistan Staphylococcus aureus (MRSA): a briefing for acute care hospitals and nursing facilities. The AHA Technical Panel on Infections within Hospitals. Infect Control Hosp Epidemiol 1994; 15: $105-113$

3. Dominguez MA, De Lencastre H, Linares J, Tomasz A. Spread and maintenance of a dominant methicillin-resistant Staphylococcus aureus (MRSA) clone during an outbreak of MRSA disease in Spanish hospital. J Clin Microbiol 1994; 32: 2081-2087.

4. Teixeira LA, Resende CA, Ormonde LR et al. Geographic spread of epidemic multiresistant Staphylococcus aureus clone in Brazil. $J$ Clin Microbiol 1995; 33: 2400-2404.

5. Neu HC. The crisis in antibiotic resistance. Science 1992; 257 1064-1073

6. Noel GJ, Kreiswirth BN, Edelson PJ et al. Multiple methicillinresistant Staphylococcus aureus strains as a cause for single outbreak of severe disease in hospitalized neonates. Pediatr Infect Dis $J$ 1992; 11: 184-188.

7. Menzies RE, Cornere BM, MacCulloch D. Adaptation of methicillin-resistant Staphylococcus aureus during antibiotic therapy. J Antimicrob Chemother 1989; 23: 923-927.

8. Casewell MW, Hill RLR. Mupirocin ('Pseudomonic acid') a promising new topical antimicrobial agent. $J$ Antimicrob Chemother 1987; 19: 1-5.

9. Layton $\mathrm{MC}$, Patterson JE. Mupirocin resistance among consecutive isolates of oxacillin-resistant and borderline oxacillinresistant Staphylococcus aureus at a University Hospital. Antimicrob Agents Chemother 1994; 38: 1664-1667.

10. Santos-Filho L, Silva-Sader H, Bortolotto VI, Gontijo-Filho PP, Pignatari AC. Analysis of the clonal diversity of Staphylococcus aureus methicillin-resistant strains isolated at João Pessoa, state of Paraiba, Brazil. Mem Inst Oswaldo Cruz 1996; 91: $101-105$.

11. Kloos WE, Schleifer KH. Genus IV. Staphylococcus. In: Sneath PHA, Mair NS, Sharpe ME, Holt JG (eds) Bergey's Manual of systematic bacteriology. Baltimore, Williams and Wilkins. 1996: 1013-1035.

12. National Committee for Clinical Laboratory Standards. Performance standards for antimicrobial disk susceptibility test M2-A5, 5th edn, V. 13, No. 24. Villanova, PA, National Committee for Clinical Laboratory Standards. 1993.

13. National Committee for Clinical Laboratory Standards. Methods for dilution antimicrobial susceptibility tests for bacteria that grow aerobically, M7-A2, 2th edn. Approved standards. Villanova, PA, National Committee for Clinical Laboratory Standards. 1990.

14. De Lencastre H, Figueiredo AMS, Urban C, Rahal J, Tomasz A. Multiple mechanisms of methicillin resistance and improved methods for detection in clinical isolates of Staphylococcus aureus. Antimicrob Agents Chemother 1991; 35: 632-639.

15. Sambrook J, Fritsch EF, Maniatis T. Molecular cloning a laboratory manual, 2nd edn. Cold Spring Harbor, NY, Cold Spring Harbor Laboratory Press. 1989.

16. Dyke $\mathrm{KGH}$, Curnock SP, Golding M, Noble WC. Cloning of the gene conferring resistance to mupirocin in Staphylococcus aureus. FEMS Microbiol Lett 1991; 77: 195-198.

17. Kreiswirth BJ, Kornblum J, Arbeit RD et al. Evidence for a clonal origin of methicillin resistance in Staphylococcus aureus. Science 1993; 259: 227-230.

18. Matthews PR, Reed KC, Stewart PR. The cloning of chromosomal DNA associated with methicillin and other resistances in Staphylococcus aureus. J Gen Microbiol 1987; 133: 1919-1929.

19. Figueiredo AMS, $\mathrm{Ha} \mathrm{E}, \mathrm{Kreiswirth} \mathrm{BN}$ et al. In vivo stability of heterogeneous expression classes in clinical isolates of methicillin-resistant staphylococcal. $J$ Infect Dis 1991; 164: $883-887$

20. De Lencastre H, Couto I, Santos I, Melo-Cristino J, TorresPereira A, Tomasz A. Methicillin-resistant Staphylococcus aureus disease in a Portuguese hospital: characterization of clonal types by a combination of DNA typing methods. Eur $J$ Clin Microbiol Infect Dis 1994; 13: 64-73.

21. Gilbart J, Perry CR, Slocombe B. High-level mupirocin resistance in Staphylococcus aureus: evidence for two distinct isoleucyl- tRNA synthetases. Antimicrob Agents Chemother 1993; 37: 32-38.

22. Netto dos Santos KR, de Souza Fonseca L, Gontijo-Filho PP Emergence of high-level mupirocin- resistance in methicillinresistant Staphylococcus aureus isolated from Brazilian university hospitals. Infect Control Hosp Epidemiol 1996; 17 813-816.

23. Soares MJS, Tokumaru-Miyazaki NH, Noleto ALS, Figueiredo AMS. Enterotoxin production by Staphylococcus aureus clones and detection of Brazilian epidemic MRSA clone (III::B:A) among isolates from food handler workers. $J$ Med Microbiol 1997; 46: 214-221.

24. Sanches IS, Ramirez M, Troni $\mathrm{H}$ et al. Evidence for the geographic spread of methicillin-resistant Staphylococcus aur eus clone between Portugal and Spain. J Clin Microbiol 1995; 33: $1243-1246$

25. Morton TM, Johnston JL, Patterson J, Archer GL. Characterization of a conjugative staphylococcal mupirocin resistance plasmid. Antimicrob Agents Chemother 1995; 39: 1272-1280.

26. Mondino PJ, Azevedo MLB, Santos KRN, Fonseca LS, Bastos MCF, Giamiagi-deMarval $M$. Detection of a conjugative plasmid involved in high-level mupirocin-resistance in methicillin-resistant Staphylococcus aureus, 97th Meeting of the American Society for Microbiology, 1997. Washington, DC American Society for Microbiology. Abstract A-117, p. 21. 